\title{
Mortality in Female and Male French Olympians
}

\section{A 1948-2013 Cohort Study}

\author{
Juliana Antero-Jacquemin, ${ }^{\star \ddagger} \mathrm{MSc}$, Grégoire Rey, ${ }^{\S} \mathrm{PhD}$, Andy Marc, ${ }^{\dagger} \mathrm{MSc}$, Frédéric Dor, ${ }^{\dagger} \mathrm{PhD}$, \\ Amal Haïda, ${ }^{\dagger \|} \mathrm{MSc}$, Adrien Marck, ${ }^{\dagger} \mathrm{MSc}$, Geoffroy Berthelot, ${ }^{\dagger \ddagger} \mathrm{PhD}$, Alain Calmat, ${ }^{\circledR} \mathrm{MD}$, \\ Aurélien Latouche, ${ }^{\#} \mathrm{PhD}$, and Jean-François Toussaint, ${ }^{\dagger \neq * \star} \mathrm{MD}, \mathrm{PhD}$ \\ Investigation performed at Institut de Recherche bioMédicale \\ et d'Epidémiologie du Sport, Paris, France
}

\begin{abstract}
Background: Whereas intense physical activity has been associated with deleterious effects on elite athletes' health, in particular due to cardiovascular anomalies, long-term follow-ups have suggested lower mortality rates among elite athletes. Causes of death for French Olympic athletes and female elite athletes have not been studied.
\end{abstract}

Hypothesis/Purpose: We aimed to measure overall and disease-specific mortality of French female and male Olympians compared with the French general population. We hypothesize that Olympians, both women and men, have lower mortality rates.

Study Design: Cohort study; Level of evidence, 3.

Methods: French elite athletes (601 women and 1802 men) participating in summer or winter Olympic Games from 1948 to 2010 had their vital status verified by national sources and were followed until 2013. Causes of death were obtained via the National Death registry from 1968 to 2012. Overall and disease-specific mortalities of Olympians were compared with those of the French general population through standardized mortality ratios (SMRs) and 95\% Cls. Olympians' observed and expected survivals were illustrated by Kaplan-Meier curves.

Results: At the endpoint of the study, 13 women and 222 men had died. Overall mortality in Olympians compared with that of their compatriots was 51\% lower (SMR, 0.49; 95\% Cl, 0.26-0.85) among women and 49\% lower (SMR, 0.51; 95\% Cl, 0.450.59) among men. Olympic athletes' survival is significantly superior to that of the French general population (women, $P=.03$; men, $P<.001$ ). According to the total deaths occurring from 1968 to 2012 (12 among women, 202 among men), female Olympians died from neoplasm (50.0\%), external causes (33.3\%), and cardiovascular diseases (16.6\%). The main causes of death among men were related to neoplasms (36.1\%), cardiovascular diseases (24.3\%), and external causes (14.4\%). Regarding the main causes of mortality among male Olympic athletes, the SMRs were as follows: 0.55 for neoplasms $(95 \% \mathrm{Cl}, 0.43-0.69)$, 0.55 for cardiovascular diseases $(95 \% \mathrm{Cl}, 0.41-0.73)$, and 0.66 for external causes $(95 \% \mathrm{Cl}, 0.44-0.94)$.

Conclusion: French Olympians live longer than their compatriots: A lower overall mortality of similar magnitude is observed among male and female athletes compared with the general population. The main causes of death in French Olympians are neoplasms, cardiovascular diseases, and external causes.

Keywords: overall mortality; disease-specific mortality; elite athletes; epidemiology

Participants in the Olympic Games are a specific population owing to the selection process they undergo. Olympic athletes are the best competitors from each country, athletes who demonstrate rare physiological aptness and physical traits, ${ }^{4}$ suggesting athletic predispositions (both genetic and environmental $)^{36}$ and high levels of training for long periods. ${ }^{16}$

Sport-related risks expose Olympians to specific outcomes: These athletes possibly have higher mortality due

The American Journal of Sports Medicine, Vol. 43, No. 6 DOI: 10.1177/0363546515574691

(C) 2015 The Author(s) to cardiovascular anomalies, ${ }^{8,26,35}$ neurologic sequelae resulting from recurrent concussions in some disciplines, ${ }^{17,21}$ or use of doping agents. ${ }^{6,29}$ In addition, high forces in certain sports may increase the probability of fatal events due to accidents and collisions. ${ }^{9,11}$

However, a recent meta-analysis on athletes' mortality evidenced that elite athletes live longer than their compatriots. ${ }^{14}$ French Olympians were not part of the cohorts included in those studies. In addition, there is a lack of studies considering female athletes, and very few studies have analyzed athletes' causes of deaths or submitted vital status to national certification.

We aimed to assess the overall and cause-specific mortality of female and male French Olympic athletes 
compared with their compatriots in the French general population. We hypothesized that French Olympians, both women and men, will have a lower mortality.

\section{METHODS}

\section{Study Design}

Retrospective cohort study of French male and female Olympians.

\section{Participants}

The study cohort consisted of all women and men who represented France in the summer or winter Olympic Games after World War II-from 1948 up to 2010-and whose vital status was validated by the National Registry of Identification of Physical Persons (RNIPP).

\section{Data Collection}

All French athletes participating in at least 1 Olympic Games from 1948 up to 2010 were identified. Their biographical information came from reliable historians' sources. ${ }^{5}$ These data were compared and confirmed with data from the International Olympic Committee (Olympic.org) and data from each official website of international federations that archive athletes' biographies.

The identity information and vital status of the study athletes were obtained from 1948 up to January 1, 2013 (study endpoint) via the RNIPP from the National Institute of Statistics and Economical Studies (INSEE), which inventories life status of French citizens living in or out of the French territory. Vital status was also followed up for Olympians who were born abroad but competed in the Olympic Games for France, as well as Olympians who emigrated. Subjects who could not have their vital status properly certified by national sources were not included in the study (Figure 1). Such exclusions were homogeneous during the studied period for both sexes.

The cause of death of each deceased subject was obtained from the Centre for epidemiology on medical causes of death (CépiDc), which has registered the causes of all deaths occurring in French territory since 1968. Causes of death occurring abroad or before 1968 or in 2012 and later were not currently accessible due a 2-year lag between the availability of death status and its corresponding cause. Therefore, the cohorts' causes of death were obtained from 1968 up to January 1, 2012 (Figure 1 ). The vital status of Olympians who died abroad was identified even though the cause of their death could not be accessed.

This study was approved by the Advisory Committee on Information Processing in Research in the Field of Health (CCTIRS) and the French National Commission for Data Protection and Liberties (CNIL).

\section{Statistical Analysis}

Descriptive analyses of the study cohort were expressed as means ( $\pm \mathrm{SD})$ and proportions $(\%)$ when suitable. We compared the mortality of French Olympic athletes with that of the French general population using two methods: (1) overall and disease-specific standard mortality ratio (SMR) and its $95 \%$ confidence interval ${ }^{14}$ and (2) KaplanMeier curves to illustrate the observed and the expected survival rate of Olympians. ${ }^{33}$

The SMR allows comparison of the mortality of the studied cohort with that of the total population containing this cohort, ${ }^{22}$ with age and period adjustment. In practical terms, SMR is the ratio between the number of deaths observed in the Olympic cohort and the number of expected deaths if the Olympians had the same death rates as the French population. Death rates of the general population were assessed via CépiDc. Individuals in a cohort differ in the time of risk exposure along their follow-up. Hence, Olympian personyear was calculated, which was defined as the actual time at risk, in years, of Olympians' follow-up. Therefore, the SMR denominator was calculated by multiplying French death rates by the Olympian person-years for the corresponding age group and period for each sex. Time was categorized in 1-year intervals from 1948 to 2013. Age groups were calculated by 5-year intervals from 15-19 years up to 100-104 years. The study athletes' follow-up started with the date of their first participation in the Olympic Games and finished with their date of death (if concerned) or with the study endpoint. An SMR equal to 1.0 means that the number of observed deaths equals that of expected cases. If lower than 1.0, the SMR indicates a lower mortality of Olympians compared with the general population. The $95 \%$ confidence intervals were calculated using the exact method. ${ }^{22}$

The Kaplan-Meier expected survival was based on the French general population death rates, and the difference with the Olympic athletes' observed survival was assessed through the log-rank test. ${ }^{31} P$ values of $<.05$ were considered to indicate statistical significance for all analyses.

\footnotetext{
*Address correspondence to Juliana da Silva Antero-Jacquemin, MSc, IRMES, Institut de Recherche bioMédicale et d'Epidémiologie du Sport, INSEP, Institut National du Sport, de l'Expertise et de la Performance, 11 avenue du Tremblay, 75012 Paris, France (e-mail: juliana.antero@insep.fr).

'Institut de Recherche bioMédicale et d’Epidémiologie du Sport (IRMES), Institut National du Sport de l'Expertise et de la Performance (INSEP), Paris, France.

‡Université Paris Descartes, Paris, France.

§INSERM, Centre for Epidemiology on Medical Causes of Death (CépiDc), Le Kremlin-Bicêtre, France.

"Université de Rouen, Rouen, France.

Comité National Olympique Sportif Français (CNOSF), Paris, France.

"Conservatoire National des Arts et Métiers (cnam), Paris, France.

${ }^{*}$ Centre d'investigations en médécine du sport (CIMS), Paris, France.

One or more of the authors has declared the following potential conflict of interest or source of funding: This work was supported by grant from the Ministry of Sports, Youth, Popular Education and Community Life of France (Project No. 12-R-10).
} 


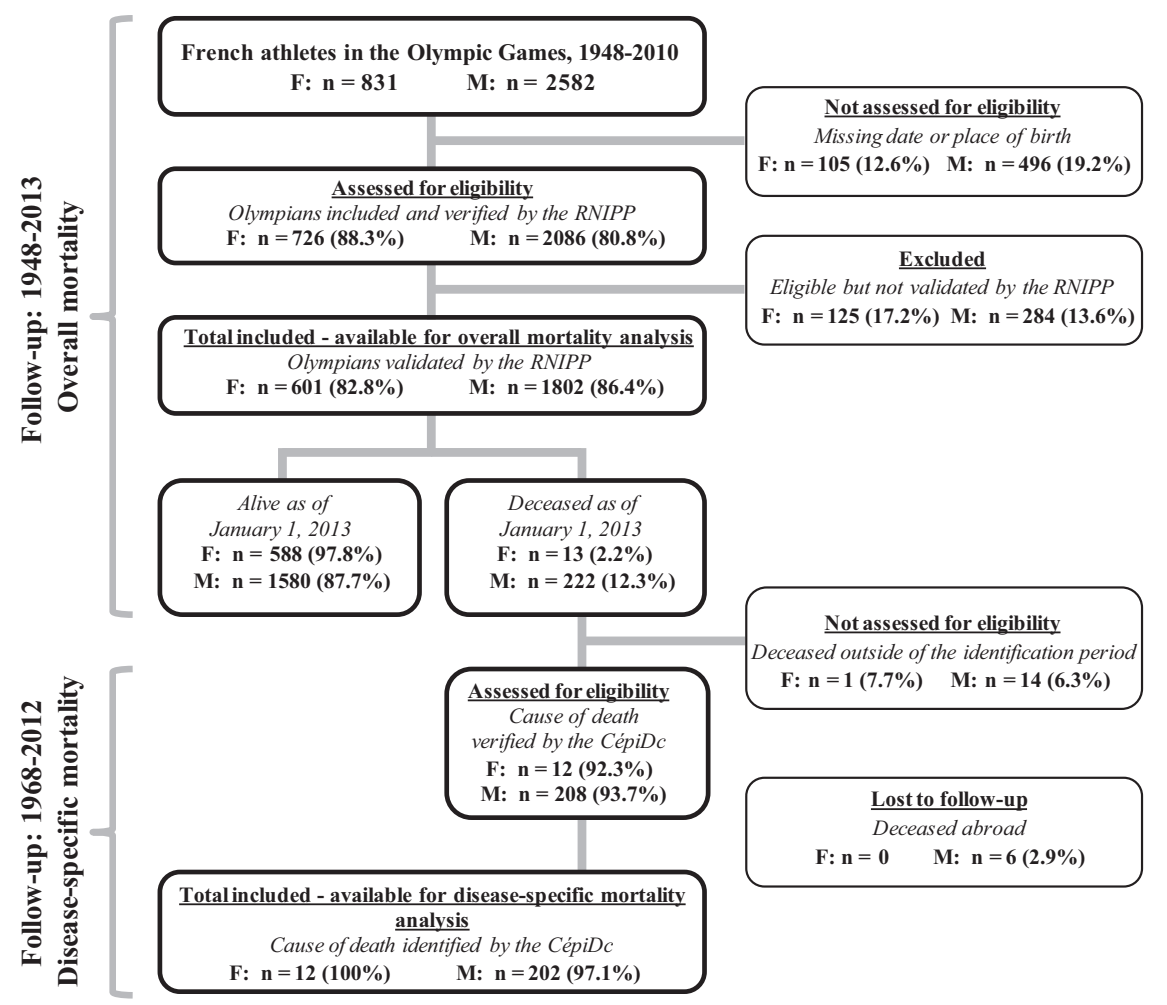

Figure 1. Flow diagram for overall and disease-specific mortality follow-up among the study cohort of female (F) and male (M) French Olympic athletes. CépiDc, Centre for epidemiology on medical causes of death; RNIPP, National Registry of Identification of Physical Persons.

\section{Scenario}

To address subjects who were excluded from the study due to absence of vital status official validation, we recalculated overall SMR analyses, adding all the Olympians who had been excluded (Figure 1). We performed overall mortality analyses assuming as true the vital status from sources monitoring Olympians' deaths (every official international federation's website and Olympic historian sources). ${ }^{5}$

\section{Disease-Specific Mortality}

To determine the disease-specific mortality, we compared each cause of death found among Olympians with the specific mortality rate of the general population by calculating SMRs for the available period, 1968 to 2012. Causes of deaths were classified according to the International Classification of Diseases (ICD) (8th revision before 1978, 9th revision between 1979 and 1999, 10th revision after 2000).

\section{Age Effect}

To analyze age-dependent differences in Olympians' mortality, SMR values were grouped according to 10-year age intervals from 25-34 up to 85-94 years. Age groups younger than 25 years or older than 95 years were not studied because they accounted for only 2 deaths among women and men. $\mathrm{R}$ software v2.14.0 was used for the analysis.

\section{RESULTS}

\section{Overall Mortality}

The analyses were performed on 601 female and 1802 male French Olympians whose vital status was validated by national sources. Among those, 235 ( $\mathrm{n}=13$ women; $\mathrm{n}=$ 222 men) died before the study endpoint. The characteristics of the study cohort are presented in Table 1 . The mean (SD) follow-up time for Olympians who were alive was 20.3 years $( \pm 14.6)$ for women and $26.8( \pm 16.7)$ for men. For those who died, the follow-up time was 35.5 years $( \pm 17.4)$ for women and $43.7( \pm 13.5)$ for men. The overall SMR results were 0.49 (95\% CI, 0.26-0.85, $P=.007)$ for female Olympians and 0.51 (95\% CI, 0.45-0.59, $P<.001)$ for male Olympians.

\section{Scenario}

The analyses were performed adding 125 women and 284 men whose vital status was identified by nonofficial sources, totaling 726 female and 2086 male French Olympians. Among those, 280 ( $\mathrm{n}=16$ women; $\mathrm{n}=264 \mathrm{men}$ ) had a date of death known before the study endpoint. This scenario 
TABLE 1

Cohort of French Olympic Athletes, 1948-2013

\begin{tabular}{lcc}
\hline Characteristic & $\begin{array}{c}\text { Women } \\
(\mathrm{n}=601)\end{array}$ & $\begin{array}{c}\text { Men } \\
(\mathrm{n}=1802)\end{array}$ \\
\hline No. of person-years & $12,075.6$ & $51,170.3$ \\
Age at study entry, y, mean $\pm \mathrm{SD}$ & $23.3( \pm 4.6)$ & $25.2( \pm 4.6)$ \\
Birth year range & $1920-1992$ & $1905-1991$ \\
Death year range & $1986-2012$ & $1973-2012$ \\
Age range at study endpoint, y & & \\
$\quad$ Alive & $21-92$ & $22-94$ \\
Deceased & $23-92$ & $26-95$ \\
\hline
\end{tabular}

shows a significantly lower mortality in female (SMR, 0.38; 95\% CI, 0.22-0.62, $P<.001$ ) and male (SMR, 0.51; 95\% CI, 0.45-0.57, $P<.001)$ Olympians than in the general population.

\section{Survival Estimations}

The observed and expected survival curves for female and male Olympians are illustrated in Figure 2. Olympians' observed curve is significantly different from the expected curve derived from the matched general French population for women $(P=.03)$ and men $(P<.001)$. The men's observed curve diverges and shifts to the right early in the follow-up period and narrows the gap at the end of the follow-up. The women's observed curve separates later from the expected curve and is clearly superior only at the end of the follow-up.

\section{Causes of Death}

Among all deaths observed ( $\mathrm{n}=235), 1$ woman and 14 men died after 2012. Nobody died before 1968. Among women, the causes of all deaths that occurred during the available identification period were identified. Concerning men, the cause of death was identified for 202 men; 6 men died abroad and their causes of deaths could not be established.

The SMR results are represented for each cause of death identified among female and male Olympians (Figure 3 ). The 3 causes of death observed among women were neoplasm $(50.0 \%)$, external causes $(33.3 \%)$, and cardiovascular diseases (16.6\%), without significant differences with the general population.

The main causes of death among men were neoplasms (36.1\%; SMR, 0.55 [95\% CI, 0.43-0.69]), cardiovascular diseases (24.3\%; SMR, 0.55 [95\% CI, 0.41-0.73]), and external causes (14.4\%; SMR, 0.66 [95\% CI, 0.44-0.94]). The mortality rates for these causes and for those due to mental disorders, respiratory system diseases, endocrine or nutritional diseases, and digestive system diseases were significantly lower for Olympians compared with their compatriots (Figure 3).

\section{Mortality by Age Group}

A significantly lower mortality rate was observed among male Olympians from the 25-34 to the 75-84 age groups compared with the general population (Figure 4). The lowest mortality was seen among the youngest group (SMR, 0.19; 95\% CI, 0.05-0.48). Olympians older than 85 years did not show a significant mortality difference (SMR, 0.90; 95\% CI, 0.60-1.30). The lower mortality rate in younger Olympians is based on a larger subcohort size for younger athletes than for older ones, as represented by the decreased percentage of persons-years with age (Figure 4). No significant differences with the general population were observed for age groups among female Olympians.

\section{DISCUSSION}

\section{Mortality in Female Olympians}

Our study shows a $51 \%$ lower mortality among female Olympians compared with their referents in the French population. To the best of our knowledge, this is the first study that evidences female athletes' lower mortality compared with the general population based on national certified vital status.

The lower risk of all-cause mortality found among female Olympians is similar to that of male Olympians: Both demonstrate a large survival advantage over their compatriots. Such findings highlight that male and female elite athletes share common determinants to a greater longevity, such as a predisposition to achieve elite athletic status and possibly the training and lifestyle required by Olympic participation. The survival advantage experienced by French Olympians reinforces findings of previous studies showing higher longevity among elite athletes. ${ }^{1,3,10,14}$

However, the Kaplan-Meier curves among women show a different dynamic from that of male Olympians, as women's advantage over the general population occurs later in life. Their survival deviates further from that of the general population at the end of the follow-up. That means that of the small sample of women who could be followed up beyond 60 years of age, most are still alive. Probably the advantage elite female athletes already show will widen in case of a longer follow-up.

Also singular is the narrowing between survival curves at the beginning of the women's follow-up. We expected to find a survival dynamic similar to that displayed among male Olympians, for whom the survival advantage starts with their Olympic participation-due to the cohort selection effect. ${ }^{18}$ The few deaths occurring among young women could explain such narrowing, even though the mortality analysis by age groups does not show any significant difference by age.

Women's disease-specific mortality also presents a particularity regarding the external causes of deaths (which comprise deaths from accidents, falls, homicides, and suicides). Whereas the main causes of deaths observed in male Olympians have analogous proportions to the main causes in the general population, the external causes among female Olympians are in larger proportions than in the general population. Nevertheless, no mortality difference by specific cause of death was shown among women.

Our results, based on very few deaths, certainly give rise to limited interpretation and analysis. Hence, the 
A

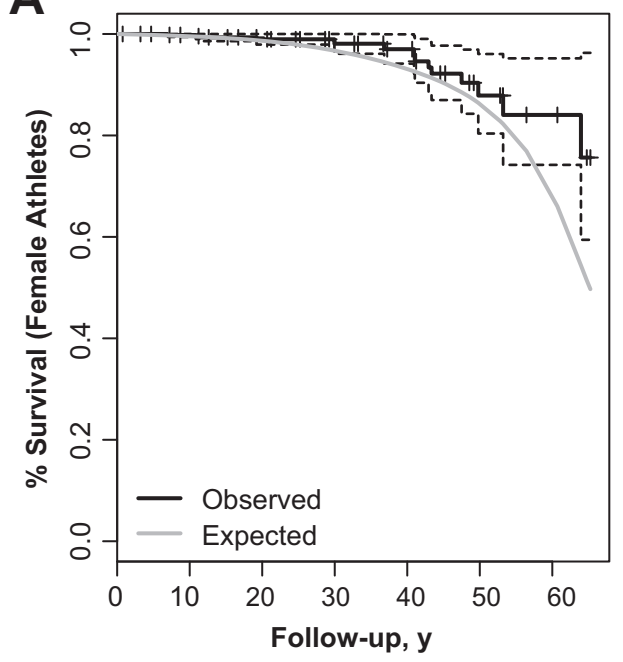

B

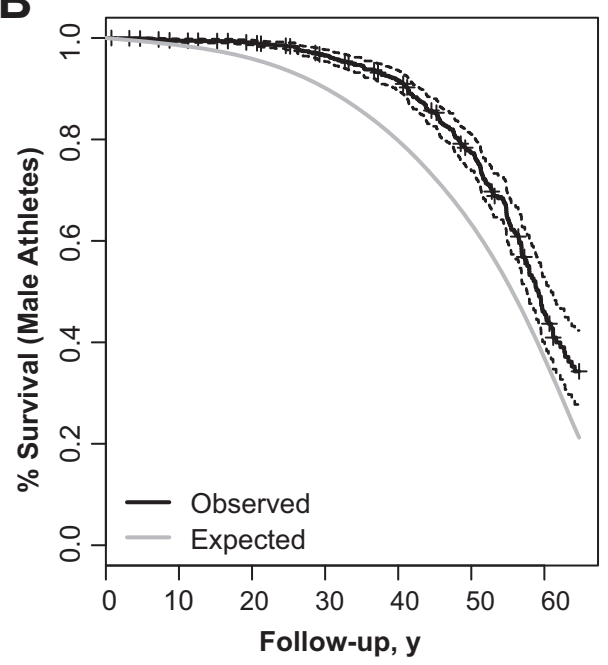

Figure 2. Observed and expected survival curves for French (A) female and (B) male Olympic athletes. The observed survival rate is represented by the solid black curve and its dashed confidence interval. The gray curve refers to the expected survival rate derived from the matched general French population.

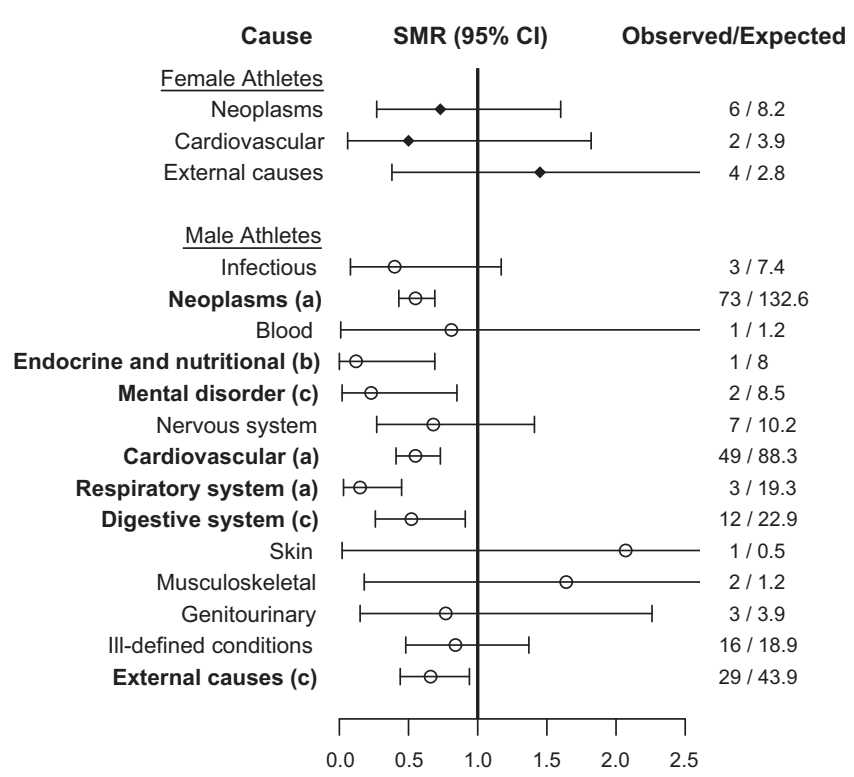

Figure 3. Disease-specific mortality of French Olympic athletes from 1968 to 2012. Cause of death was classified according to the International Classification of Diseases (8th revision before 1978, 9th revision between 1979 and 1999, 10th revision after 2000). The vertical bold line represents the general population reference value (standard mortality ratio $[S M R]=1$ ). The causes of death that were significantly different from those of the general population are in bold. (a) $P<.001$; (b) $P<.01$; (c) $P<.05$.

findings regarding women's survival dynamics, age dependence, and disease-specific mortality reveal a path requiring further investigation. Yet this is the largest cohort of elite sportswomen ever followed up, corresponding to $85 \%$

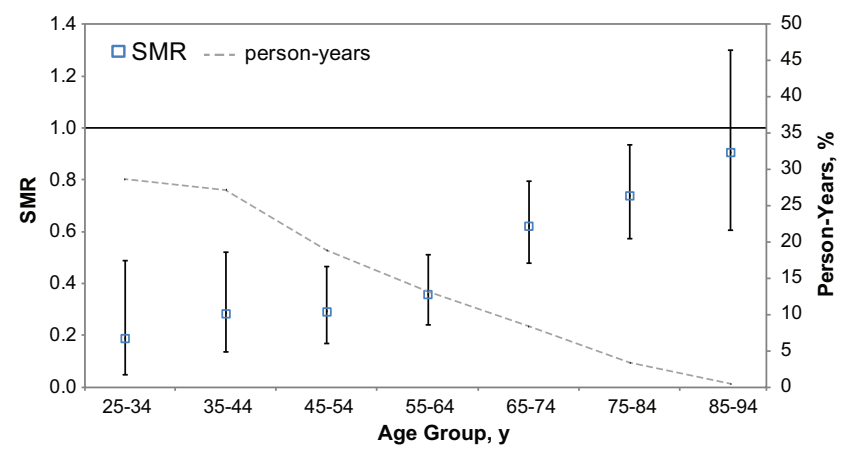

Figure 4. Overall standardized mortality ratios (SMRs) and 95\% confidence intervals by 10 -year age intervals for French athletes participating in the Olympic Games from 1948 to 2010. The horizontal line represents the general population reference value $(S M R=1)$. The dashed line represents the percentage of person-years followed.

of all cohorts of sportswomen accounted for in a recent meta-analysis, ${ }^{14}$ and it provides evidence of higher longevity among French female Olympians.

\section{Mortality in Male Olympians}

We found consistently lower mortality rates for male Olympians versus their male compatriots until advanced ages. The risk of all-cause mortality among men by age group varies from $81 \%$ lower at younger ages to $27 \%$ lower in the 75- to 84-year age group, and there is no difference with the general population at 85 years of age or older. Such age-related mortality patterns could be due to a survival selection process. At younger ages, Olympians are at the maximum of their capacity. ${ }^{4}$ With aging a selection 
also operates in the general population, and at very advanced ages both groups include highly selected individuals. A study comparing Olympians to supercentenarians shows that among worldwide participants in the Olympic Games since 1896, none has lived to 110 years. $^{2}$ Olympians live longer but are not the longest-lived.

The overall mortality found among male Olympians is mainly associated with lower risk of 3 major causes of deaths seen among them: neoplasms, cardiovascular diseases, and external causes (which are 34\%-45\% lower than those found in the general population). In addition, French male Olympians display a significantly lower mortality from mental disorders, endocrine or nutritional diseases, and digestive system diseases and an $85 \%$ lower risk of mortality due to respiratory system diseases. The mortality from other causes is not statistically different from that of the general population. Rare causes of death, however, are based on a few deaths only, resulting in large confidence intervals that are hardly interpretable.

The benefits of moderate physical activity are well known for preventing cardiovascular problems. ${ }^{45}$ Intense training, however, has been associated with cardiovascular events: coronary remodeling, ${ }^{7}$ artery calcification, ${ }^{25}$ and atrial fibrillation and flutter, ${ }^{26}$ although an association has not been clearly established. ${ }^{20,38}$ A triggered arrhythmia threshold has been proposed, ${ }^{8}$ but the 1500 lifetime hours of intense exercise are largely exceeded by Olympic athletes. ${ }^{16}$ Hence, a U-shape curve has been proposed for elite athletes, relating training load and cardiovascular risk. ${ }^{35}$

Here we show a $45 \%$ lower mortality from cardiovascular diseases among male Olympians compared with the general male population. This long-term outcome for French Olympians is consistent with previous findings. ${ }^{3,24,39}$ Indeed, a 4to 17-year follow-up of Italian Olympians did not show any deterioration in left ventricular function or an increased rate of cardiovascular events. ${ }^{30}$ There is growing evidence that the cardiovascular benefits of practicing sports at an elite level outweigh potential negative effects. ${ }^{14,20,37}$ These elements may suggest another association between health effect and exercise load: an L-shape for the relation between risk and exercise, where there is no risk resurgence at the highest exercising levels for previously healthy subjects.

These results, however, should be interpreted in light of the heterogeneity of sports within the cohort, given that we sampled a wide range of athletes participating in activities from pure anaerobic to fully aerobic sports.

A two-way relation is possibly operating among Olympians: Rare traits enable high-level sport practice, and high-level sport conditions maintain capacities that reduce cardiac and overall mortality.

\section{Cohort Selection Effect}

Performance selection processes result in selecting healthy subjects who are in a favorable environment and have genetic predispositions. ${ }^{44}$ Olympians constitute the fittest athletes who have a highly unusual set of physical and psychological traits. ${ }^{32,40}$ The presence of genotypes related to lower disease risk among elite athletes has been debated. ${ }^{15,46}$ The Olympians' survival advantage affects individuals who have undergone an inevitable selection process. It therefore needs to be cautiously interpreted, because this advantage may not be extendable to the general population. In other studies, highly selected male cohorts showed comparably low overall mortality, including in comparison with healthy references. ${ }^{13,39}$ The comparison of Olympians with their compatriots reveals the effect of a phenotypic selection on death rates. The relatively lower mortality found is certainly enhanced by the existence of chronically ill subjects in the reference population. This situation is symmetrical to the selection of a control group in clinical studies of rare polygenic diseases. ${ }^{32}$

\section{Health-Enhancing Physical Activity}

Dose-response relations between training intensity and health benefits are not well established, ${ }^{28,34,35}$ but the overexposure to high-level training does not seem to be deleterious to French Olympians. This suggests that elite athletes are probably capable of adapting to intense activity ${ }^{27}$ and still derive benefits from it, at least in terms of longevity. Intense sports participation has nonetheless been associated with increased risk of musculoskeletal and connective tissue diseases. ${ }^{42}$ Even if such risk does not seem to affect survival rates-here only 2 deaths were related to musculoskeletal diseases-it remains unclear whether Olympians' higher longevity is associated with higher morbidities and to what extent the presence of morbidities may affect their quality of life.

No significant excess death was observed for any specific cause, in contrast with previous findings of higher mortality due to amyotrophic lateral sclerosis among Italian soccer players, ${ }^{41}$ neurodegenerative diseases among American football players, ${ }^{21}$ and suicide among Swedish power sport athletes. ${ }^{23}$

The lowest mortality age group corresponds to the years when most Olympians are still active, contrasting with the higher mortality found during cyclists' careers. ${ }^{24}$ Most Olympians spend much of their training indoors or in controlled outdoor environments, a safer condition than road cycling, which may explain such divergence. Hence, it seems that if sports are not directly unsafe, high-intensity training does not provide further deleterious effects throughout life on previously healthy people.

\section{Maintaining a Healthy Lifestyle After a Sports Career}

We have not assessed French elite athletes' lifestyles after their career. Previous studies, however, have reported that athletes usually maintain healthier habits than the general population before, during, and after their career, ${ }^{12}$ such as low smoking rates, good nutrition, and exercising. ${ }^{19}$ In addition, the Olympians' level of fitness may constitute a "health bank"; this advantage may last over years, as shown by the lower mortality across male Olympians' age groups. Human capacities decay with aging ${ }^{4}$ but elite athletes start from a higher level. Hence, for a formerly well-trained person, physical activity may be effortlessly performed, allowing him or her to keep practicing throughout life. ${ }^{19}$ 


\section{Use of Performance-Enhancing Substances}

The use of substances designed to enhance athletic performance is as old as the human aspiration to break limits, and its use during the Olympics dates back to the first Games. ${ }^{43}$ The first listing of prohibited substances was made in the $1960 \mathrm{~s}$, but it has restricted doping only partially; however, the adverse health-related effects of substances have been shown. ${ }^{6}$ We do not know which athletes in our cohort used doping agents, and therefore it is difficult to assess to what extent the use of such substances might have minimized the large survival benefit experienced by French Olympic athletes.

\section{Methodological Considerations}

No causal inference can be made between Olympic participation and the observed lower mortality of Olympians, particularly because only age and period could be adjusted for potential confounding factors. We simulated a scenario to address the possible changes in our results that the excluded athletes could cause. The lower mortality found by adding excluded Olympians is similar to the outcomes presented here, with similar results among men and even lower mortality among women. Therefore, it is unlikely that the athletes excluded from the study may overturn the overall mortality results presented here. Yet, we acknowledge a limitation with regard to the deaths that occurred abroad or too recently for causes to be identified. Our method's advantages rely on an extensive follow-up of athletes of both sexes and of the highest performance levels based on national vital status certification.

\section{Perspectives}

Disease-specific studies assessing larger samples of elite sportswomen are necessary to understand better the causes of death that are associated with their lower overall mortality. Analytical studies controlling the factors that might influence elite athletes' mortality are now required to decipher this phenomenon: sport type, country, training methods, performance level, biometrics, career period, doping practice, and postcareer lifestyle, including athletes' quality of life.

\section{CONCLUSION}

French Olympians live longer than their compatriots: A lower overall mortality of similar magnitude is observed among sportswomen and sportsmen compared with their compatriots. The main causes of death observed among Olympians are neoplasms, cardiovascular diseases, and external causes. These 3 major causes of death are significantly lower among male Olympians than in the general population. Studies based on larger cohorts of women elite athletes are required for better comprehension of their survival advantage over their compatriots.

\section{ACKNOWLEDGMENT}

The authors thank Guillaume Sauliere for enhancing the presentation of the figures. The authors thank the Institute National du Sport de l'Expertise et de la Performance (INSEP) for its full support.

\section{REFERENCES}

1. Abel EL, Kruger ML. The healthy worker effect in major league baseball revisited. Res Sports Med Print. 2006;14(1):83-87.

2. Antero-Jacquemin JD, Berthelot G, Marck A, Noirez P, Latouche A, Toussaint J-F. Learning from leaders: life-span trends in Olympians and supercentenarians [published online August 20, 2014]. J Gerontol A Biol Sci Med Sci. doi:10.1093/gerona/glu130.

3. Antero-Jacquemin J, Desgorces FD, Dor F, et al. Row for your life: a century of mortality follow-up of French Olympic rowers. PloS One. 2014;9(11):e113362.

4. Berthelot G, Len S, Hellard P, et al. Exponential growth combined with exponential decline explains lifetime performance evolution in individual and human species. Age Dordr Neth. 2012;34(4):10011009.

5. Clarke PM, Walter SJ, Hayen A, Mallon WJ, Heijmans J, Studdert DM. Survival of the fittest: retrospective cohort study of the longevity of Olympic medallists in the modern era. BMJ. 2012;345:e8308.

6. Deligiannis A, Björnstad H, Carre F, et al. ESC study group of sports cardiology position paper on adverse cardiovascular effects of doping in athletes. Eur J Cardiovasc Prev Rehabil. 2006;13(5):687-694.

7. Ector J, Ganame J, Merwe N van der, et al. Reduced right ventricular ejection fraction in endurance athletes presenting with ventricular arrhythmias: a quantitative angiographic assessment. Eur Heart J. 2007;28(3):345-353.

8. Elosua R, Arquer A, Mont $L$, et al. Sport practice and the risk of lone atrial fibrillation: a case-control study. Int J Cardiol. 2006;108(3):332-337.

9. Engebretsen L, Steffen K, Alonso JM, et al. Sports injuries and illnesses during the Winter Olympic Games 2010. Br J Sports Med. 2010;44(11):772-780.

10. Fafian J. Mortality experience of National Basketball Association players. North Am Actuar J. 1997;1(4):45-48.

11. Findling JE, Pelle KD. Encyclopedia of the Modern Olympic Movement. Westport, CT: Greenwood Publishing Group; 2004:648.

12. Fogelholm M, Kaprio J, Sarna S. Healthy lifestyles of former Finnish world class athletes. Med Sci Sports Exerc. 1994;26(2):224-229.

13. Gajewski AK, Poznańska A. Mortality of top athletes, actors and clergy in Poland: 1924-2000 follow-up study of the long term effect of physical activity. Eur J Epidemiol. 2008;23(5):335-340.

14. Garatachea N, Santos-Lozano A, Sanchis-Gomar F, et al. Elite athletes live longer than the general population: a meta-analysis. Mayo Clin Proc. 2014;89(9):1195-1200.

15. Gómez-Gallego F, Ruiz JR, Buxens A, et al. Are elite endurance athletes genetically predisposed to lower disease risk? Physiol Genomics. 2010;41(1):82-90.

16. Güllich A, Emrich E. Considering long-term sustainability in the development of world class success. Eur J Sport Sci. 2014;14(suppl 1): S383-S397.

17. Guskiewicz KM, Marshall SW, Bailes J, et al. Association between recurrent concussion and late-life cognitive impairment in retired professional football players. Neurosurgery 2005;57(4):719-726; discussion 719-726.

18. John M. Last. A Dictionary of Epidemiology. 3rd ed. Oxford, UK: Oxford University Press; 1995.

19. Kujala UM, Sarna S, Kaprio J, Tikkanen HO, Koskenvuo M. Natural selection to sports, later physical activity habits, and coronary heart disease. Br J Sports Med. 2000;34(6):445-449.

20. Kwok CS, Anderson SG, Myint PK, Mamas MA, Loke YK. Physical activity and incidence of atrial fibrillation: a systematic review and meta-analysis. Int J Cardiol. 2014;177(2):467-476. 
21. Lehman EJ, Hein MJ, Baron SL, Gersic CM. Neurodegenerative causes of death among retired National Football League players. Neurology. 2012;79(19):1970-1974.

22. Liddell FD. Simple exact analysis of the standardised mortality ratio. $J$ Epidemiol Comm Health. 1984;38(1):85-88.

23. Lindqvist A-S, Moberg T, Ehrnborg C, Eriksson BO, Fahlke C, Rosén T. Increased mortality rate and suicide in Swedish former elite male athletes in power sports. Scand J Med Sci Sports. 2014;24(6):1000-1005.

24. Marijon E, Tafflet M, Antero-Jacquemin J, et al. Mortality of French participants in the Tour de France (1947-2012). Eur Heart J. 2013;34(40):3145-3150.

25. Möhlenkamp S, Lehmann N, Breuckmann F, et al. Running: the risk of coronary events. Prevalence and prognostic relevance of coronary atherosclerosis in marathon runners. Eur Heart J. 2008;29(15):1903-1910.

26. Mont L, Elosua R, Brugada J. Endurance sport practice as a risk factor for atrial fibrillation and atrial flutter. Europace. 2009;11(1):11-17.

27. Noakes T, Spedding M. Olympics: Run for your life. Nature. 2012;487(7407):295-296.

28. O'Keefe JH, Lavie CJ. Run for your life . . . at a comfortable speed and not too far. Heart. 2013;99(8):516-519.

29. Pärssinen M, Kujala U, Vartiainen E, Sarna S, Seppälä T. Increased premature mortality of competitive powerlifters suspected to have used anabolic agents. Int J Sports Med. 2000;21(3):225-227.

30. Pelliccia A, Kinoshita N, Pisicchio C, et al. Long-term clinical consequences of intense, uninterrupted endurance training in Olympic athletes. J Am Coll Cardiol. 2010;55(15):1619-1625.

31. Peto R, Peto J. Asymptotically efficient rank invariant test procedures. J R Stat Soc Ser Gen. 1972;135(2):185.

32. Plomin R, Haworth CMA, Davis OSP. Common disorders are quantitative traits. Nat Rev Genet. 2009;10(12):872-878.

33. Pohar M, Stare J. Relative survival analysis in R. Comput Methods Programs Biomed. 2006;81(3):272-278.

34. Powell KE, Paluch AE, Blair SN. Physical activity for health: what kind? How much? How intense? On top of what? Ann Rev Public Health. 2011;32:349-365.
35. Predel H-G. Marathon run: cardiovascular adaptation and cardiovascular risk. Eur Heart J. 2014;35(44):3091-3098.

36. Ruiz JR, Gómez-Gallego F, Santiago C, et al. Is there an optimum endurance polygenic profile? J Physiol. 2009;587(pt 7):1527-1534

37. Sanchis-Gomar F, Garatachea N, Catalán P, López M, Lucia A, Serrano-Ostáriz $\mathrm{E}$. Strenuous endurance exercise and right ventricular systolic function: no evidence of long-term sequelae. Int $J$ Cardiol. 2015;179:297-298.

38. Sanchis-Gomar F, Pareja-Galeano H, Santos-Lozano A, Fiuza-Luces C, Garatachea N, Lucia A. Strenuous exercise and the heart: are we not seeing the wood for the trees? Int $J$ Cardiol. 2014;176(3): 1304-1305.

39. Sarna S, Sahi T, Koskenvuo M, Kaprio J. Increased life expectancy of world class male athletes. Med Sci Sports Exerc. 1993;25(2): 237-244.

40. Schaal K, Tafflet M, Nassif $\mathrm{H}$, et al. Psychological balance in high level athletes: gender-based differences and sport-specific patterns. PloS One. 2011;6(5):e19007.

41. Taioli E. All causes mortality in male professional soccer players. Eur $J$ Public Health. 2007;17(6):600-604.

42. Von Porat A, Roos E, Roos H. High prevalence of osteoarthritis 14 years after an anterior cruciate ligament tear in male soccer players: a study of radiographic and patient relevant outcomes. Ann Rheum Dis. 2004;63(3):269-273.

43. Wagner J. Enhancement of athletic performance with drugs: an overview. Sports Med. 1991;12(4):250-265.

44. Wang G, Padmanabhan S, Wolfarth B, et al. Genomics of elite sporting performance: what little we know and necessary advances. Adv Genet. 2013;84:123-149.

45. Wen CP, Wai JPM, Tsai MK, et al. Minimum amount of physical activity for reduced mortality and extended life expectancy: a prospective cohort study. Lancet. 2011;378(9798):1244-1253.

46. Zaidi A, Sharma S. Reduced mortality in former Tour de France participants: the benefits from intensive exercise or a select genetic tour de force? Eur Heart J. 2013;34(40):3106-3108.

For reprints and permission queries, please visit SAGE's Web site at http:/www.sagepub.com/journalsPermissions.nav 